This document is the accepted manuscript version of the following article:

Jayaratne, E. R., Meyer, N. K., Ristovski, Z. D., Morawska, L., \& Miljevic, B. (2010). Critical analysis of high particle number emissions from accelerating compressed natural gas buses.

Environmental Science and Technology, 44(10), 3724-3731. https://doi.org/10.1021/es1003186

\title{
A Critical Analysis of High Particle Number Emissions from Accelerating Compressed Natural Gas Buses
}

E.R. Jayaratne, N. K. Meyer, Z.D. Ristovski , L. Morawska and B. Miljevic

International Laboratory for Air Quality and Health

Queensland University of Technology

GPO Box 2434, Brisbane, QLD 4001, Australia

January 2010

* Corresponding author contact details:

Tel: (617) 3138 1129; Fax: (617) 31389079

Email: z.ristovski@qut.edu.au

Re-Submitted to "Environmental Science and Technology" 


\begin{abstract}
Compressed natural gas (CNG) engines are thought to be less harmful to the environment than conventional diesel engines, especially in terms of particle emissions. Although, this is true with respect to particulate matter (PM) emissions, results of particle number $(\mathrm{PN})$ emission comparisons have been inconclusive. In this study, results of on-road and dynamometer studies of buses were used to derive several important conclusions. We show that, although PN emissions from CNG buses are significantly lower than from diesel buses at low engine power, they become comparable at high power. For diesel buses, PN emissions are not significantly different between acceleration and operation at steady maximum power. However, the corresponding PN emissions from CNG buses when accelerating are an order of magnitude greater than when operating at steady maximum power. During acceleration under heavy load, PN emissions from CNG buses are an order of magnitude higher than from diesel buses. The particles emitted from CNG buses are too small to contribute to $\mathrm{PM}_{10}$ emissions or contribute to a reduction of visibility, and may consist of semivolatile nanoparticles.
\end{abstract}

Keywords: vehicle emissions, particle number emissions, diesel, CNG, 


\section{Introduction}

Compressed natural gas (CNG) engines are known to produce significantly lower emissions, such as particulate matter $(\mathrm{PM})$ and oxides of nitrogen $\left(\mathrm{NO}_{\mathrm{x}}\right)$, than conventional diesel engines and, for this reason, in recent years there has been a major drive to replace diesel powered vehicles with CNG, especially in large transport fleets. For example, over the past eight years, $50 \%$ of the transport bus fleet in Brisbane, Australia, has been gradually converted from diesel to CNG. In New Delhi, India, one of the most polluted cities in the world, the entire transport fleet was converted to CNG in 2003 resulting in some improvement in air quality in terms of suspended particulate matter, $\mathrm{CO}, \mathrm{SO}_{2}$ and $\mathrm{NO}_{\mathrm{x}}$ (1). In spite of these advantages, concerns have been expressed on the relative concentrations of ultrafine particles (particles smaller than $100 \mathrm{~nm}$ in diameter) emitted by buses operating on diesel and CNG. These small particles are important as they are able to penetrate deep into the human lung and are more toxic than larger particles (2). Therefore, from both health and environmental perspectives, there is a great incentive to study and compare particle number-size distributions in exhaust emissions, particularly, from vehicles operating on CNG fuel. As a result, there have been many studies directed at comparing particle emissions from diesel and CNG buses (3-11). Most of these studies have shown a consistency with respect to particle mass emission factors with emissions from CNG buses being less than $5 \%$ that from diesel buses when no aftertreatment devices are employed. However, there is considerable disagreement between results of particle number (PN) emission measurements. Nylund et al. (10) determined PN emission factors from diesel and CNG buses in two transient cycles. Jayaratne et al. (12) reported PN emission factors from a selection of diesel and CNG 
buses under four steady-state operating conditions. In general, PN emissions from CNG buses appear to be lower than from diesel buses, but there are some exceptions, particularly related to high engine load conditions (3, 13-15).

In the present paper, we investigate further the results from two previous studies and present new results on accelerating diesel and CNG buses in a transient cycle to identify the conditions that give rise to high PN emissions.

\section{Methods}

2.1 Study 1 was carried out on a large fleet of diesel and CNG buses operating on a dedicated busway $(14,15)$. In age, the diesel buses ranged from 6 to 23 years and included pre-Euro and Euro I Volvo B10M (engine type THD101GC; 9.6L) and Euro II Volvo B10L (engine type D10HA; 9.6L) buses, all with no after-treatment devices. The CNG buses ranged in age from 1 to 5 years and were all Euro II and III Scania (engine type OSC9G; 9.0L) buses fitted with two-way oxidation catalysts. PN and carbon dioxide $\left(\mathrm{CO}_{2}\right)$ concentrations in the exhaust plumes were measured in real time with a TSI 3025 condensation particle counter (CPC) and a Sable CA-10A analyser, both sampling at a distance of about $1.0 \mathrm{~m}$ from the kerb at a height of $0.6 \mathrm{~m}$ above the road. The response time of both instruments was $1 \mathrm{~s}$ and concentration peaks were observed as each bus travelled past. The ratio of $\mathrm{PN}$ to $\mathrm{CO}_{2}$ concentrations (Z) in the diluted plume were used as an estimate of the respective PN emission factors of the buses. For more details of the method, the sampling procedure, data analyses and interpretation and bus specifications the reader is directed to Jayaratne et al $(14,15)$. 
In a sample of 164 diesel and 98 CNG buses, the median values and standard errors of $\mathrm{Z}$ were (1265 \pm 64$)$ and (7584 \pm 258$)$, respectively, in units of millions of particles per mg of $\mathrm{CO}_{2}$. Median $\mathrm{Z}$ values were thought to be more meaningful than mean values because, as shown by Jayaratne et al. (14), the $\mathrm{Z}$ values were gamma-distributed with a long tail corresponding to a small number of spuriously high-emitting buses. This result indicates that the median PN emission from the CNG buses was over six times higher than from diesel buses. However, this should be treated with some caution, as the instruments were located at the departure end of the bus station platform which was only a few metres driving distance from where the buses stopped. Hence, all buses passed the sampling point accelerating in first or second gear. For the purposes of this study, we extend the analyses of the data obtained to buses that passed without stopping at the station.

2.2 Study 2 was conducted on a chassis dynamometer. Each bus was run at high load for about $10 \mathrm{~min}$ before commencement of testing. The opacity was measured at the tailpipe with a Maha MDO-2 opacimeter. For the emissions measurements, a continuous flow sampling method was utilized with the exhaust being directed into a primary sampling line. The $\mathrm{CO}_{2}$ concentration was measured with a non-dispersive infrared monitor from California Analytical Instruments Inc with response time and accuracy of $1 \mathrm{~s}$ and $10 \mathrm{ppm}$, respectively. The $\mathrm{PM}_{10}$ concentration was measured with a TSI 8520 Dustrak monitor. A small sample of the air from the primary line was extracted and passed through an ejector type diluter (Dekati Ltd) where it was diluted by a factor of 10 with filtered air and passed to a TSI 3022 CPC for the PN measurement. The total dilution ratio was estimated by measuring the $\mathrm{CO}_{2}$ 
concentration of the diluted air and comparing it with that in the primary line. The emission rates were calculated from the flow rates and the dilution ratio. The instantaneous speed, power and load of the bus were reported by the dynamometer. All data were recorded at $1 \mathrm{~s}$ intervals.

The emissions study was carried out in two parts. In the first, PN emissions from 13 CNG and 9 diesel buses were determined at four steady-state engine loads set at $0 \%$ (idle), $25 \%, 50 \%$ and $100 \%$ of the maximum engine power at $60 \mathrm{~km} \mathrm{~h}^{-1}$ over periods of 10 min at each load. Details of this study, including the specifications of the buses, may be found in Jayaratne et al. (12). In the second part of the study, the same buses were tested in the DT-80 transient cycle. A real test example of this urban driving cycle is shown in Fig 1. It consists of four driving type segments, indicated in the figure as I (idle), A (acceleration), D (deceleration) and C (cruise). The cycle begins with an idle period of 1 min followed by three hard acceleration segments where the vehicle accelerates from 0 to $80 \mathrm{~km} \mathrm{~h}^{-1}$ in time periods of $40-50 \mathrm{~s}$. In the first two accelerating segments, once the speed reaches $80 \mathrm{~km} \mathrm{~h}^{-1}$, it is brought to rest for a few seconds. On the third segment, the speed of the bus is held at a steady speed of $80 \mathrm{~km}$ $\mathrm{h}^{-1}$ for 1 min before decelerating to rest. In the present study, each cycle lasted about 5 min and the total distance 'travelled' by the bus was about $4 \mathrm{~km}$. Emissions were monitored and recorded at $1 \mathrm{~s}$ intervals, together with all the engine operating conditions such as speed, load and power by the dynamometer operating system. The system clock was synchronized to the emission data acquisition computers and was generally accurate to \pm 1 s. The times were further verified by noting and synchronizing the sharp increases in each exhaust emission concentration associated with each increase in speed. These measured allowed the engine operation data to be 
aligned with the emissions data to account for the time lags between the engine exhaust and the sampling point. Although transient cycles do not provide emission factors under fixed engine load conditions, they enable comparison between buses, for example between diesel buses and CNG buses at various driving conditions such as idle, acceleration and cruise.

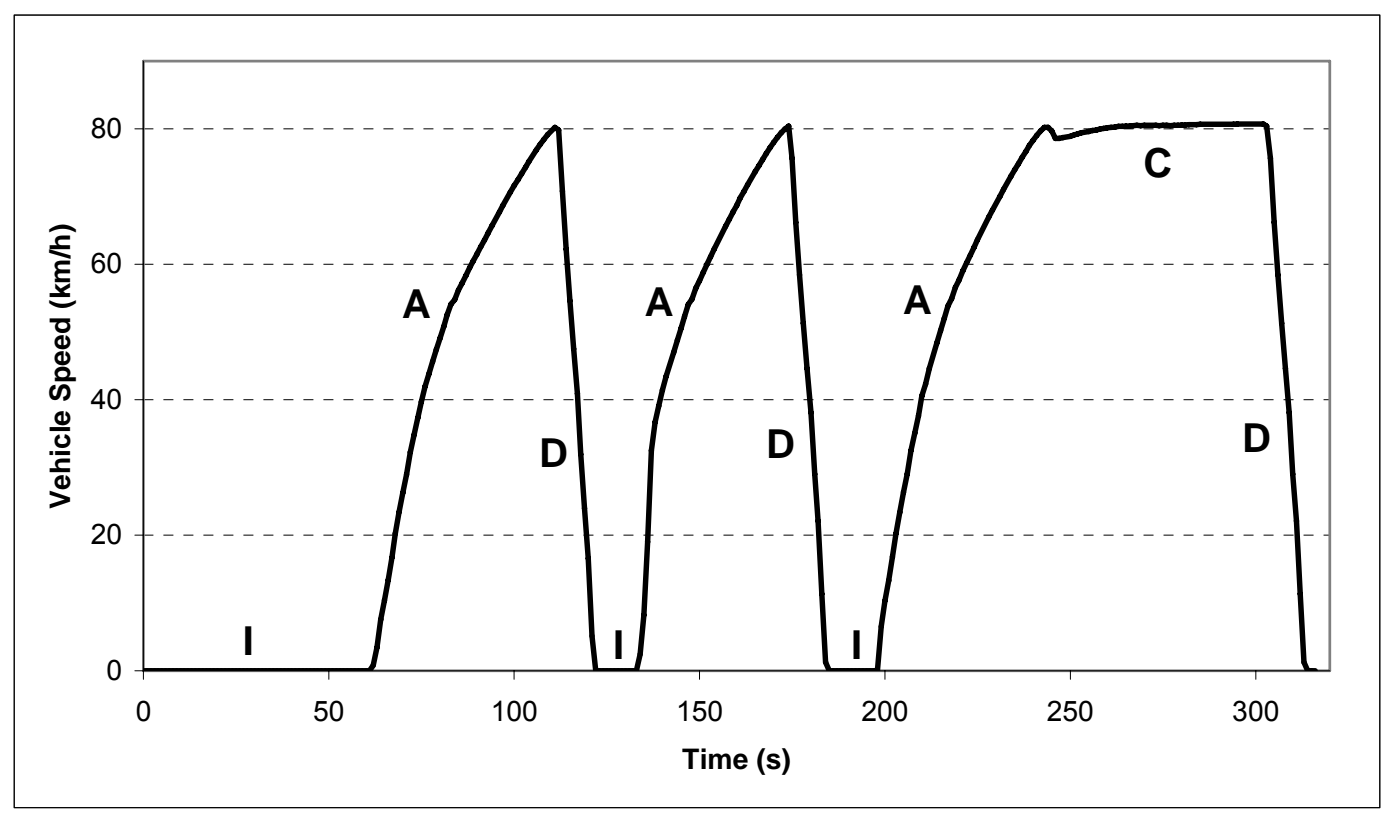

Fig 1: A real-time DT-80 Transient Test Cycle (see text for details).

For the purpose of this investigation, of the 22 buses tested, we identified 9 buses that were common to the fleet in Study 1. These consisted of 5 CNG Scania (age 3-5 years) buses and 4 diesel buses including three B10M (age 11-16 years) and one B10L (age 8 years) buses. Each bus was tested through at least 3 DT-80 cycles.

Mean PN emission rates between the two types of buses and between operating modes were compared using a Students t-test and compared at the 95\% level of confidence. 


\section{Results}

3.1 Study 1 (on-road): Real-time concentration data of $\mathrm{PN}$ and $\mathrm{CO}_{2}$ measured during the passage of 262 buses past the monitoring location were analysed.

Fig 2 shows the respective concentrations observed during two time segments that included the passage of seven buses, labelled A to G. Table 1 lists the identities of the buses, the driving conditions, the measured emission concentrations and the respective $\mathrm{Z}$ values.

The driving pattern and passage of every bus was noted visually. As mentioned earlier, most buses stopped at the station and, as the instruments were placed at the departure end of the platform, passed the monitoring point in the process of accelerating from rest. However, there were a few exceptions, such as buses B and G, which did not stop and passed the sampling point at a steady cruising speed of about $30-40 \mathrm{~km} \mathrm{~h}^{-1}$. The net values of $\mathrm{PN}$ and $\mathrm{CO}_{2}$ given in the table were calculated as step differences between the maximum and background values in Fig 2. Background values were estimated as the mean of the steady levels on either side of each peak. Note that the absolute step values of the $\mathrm{PN}$ and $\mathrm{CO}_{2}$ do not give any indication of the respective emission rates, as they are obtained under different dilution levels. However, the ratio of these two values, $\mathrm{Z}$, given in the last column, is directly proportional to the emission rate. We use the $\mathrm{Z}$ values to compare the emissions from the two types of buses under the two driving patterns - accelerating and cruising. 

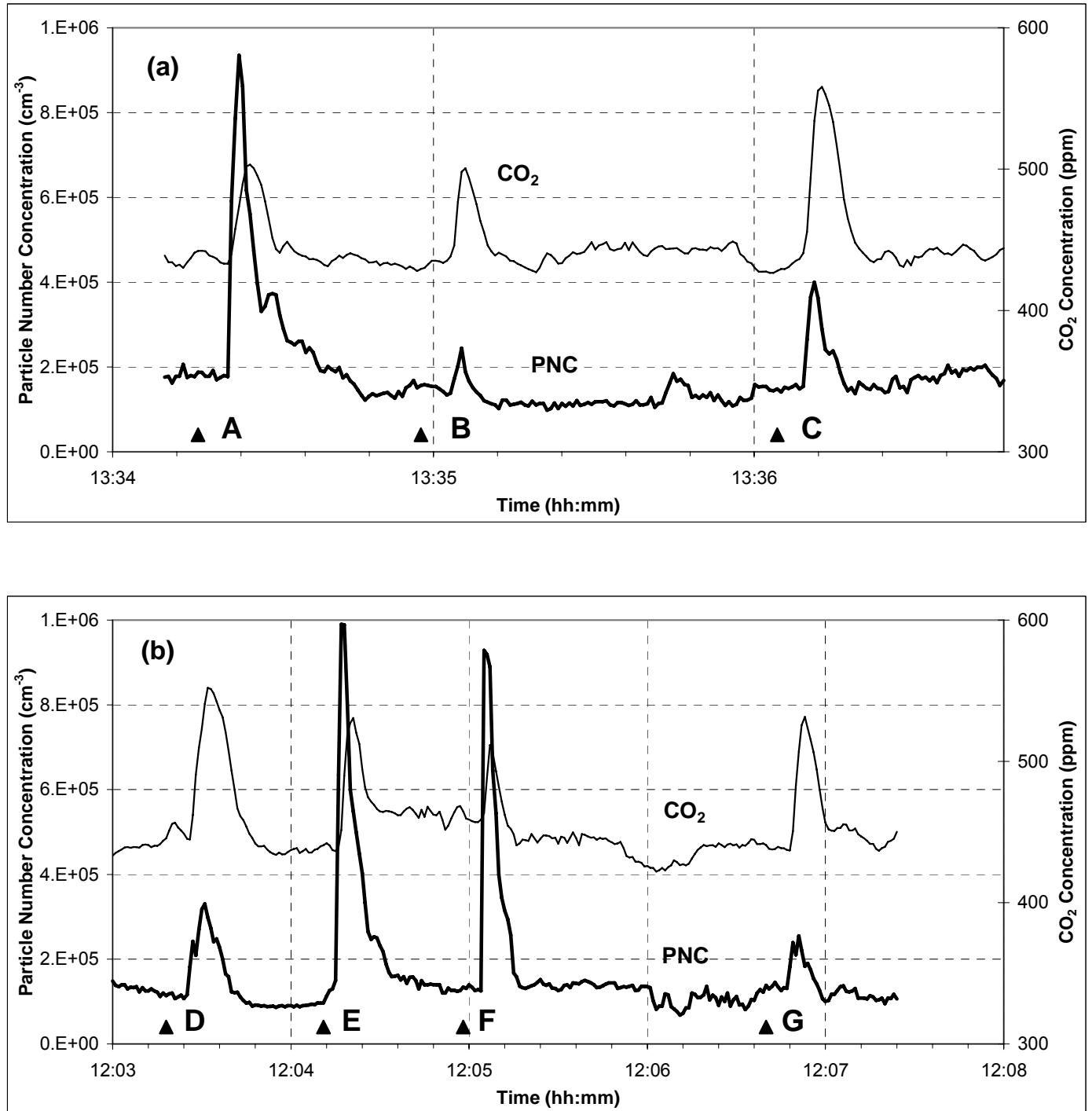

Fig 2: $\mathrm{CO}_{2}$ and $\mathrm{PN}$ concentrations measured during the passage of seven buses A-G indicated by the symbol $\boldsymbol{\Delta}$. The bus identities and emission concentrations are given in Table 1. 
Table 1: Details of buses indicated A-G in Fig 2. Each row is for a single pass of an individual bus.

\begin{tabular}{|c|c|c|c|c|c|}
\hline $\begin{array}{c}\text { Bus } \\
\text { Label }\end{array}$ & $\begin{array}{l}\text { Fuel } \\
\text { Type }\end{array}$ & $\begin{array}{l}\text { Driving } \\
\text { Condition }\end{array}$ & $\begin{array}{l}\text { Net PN } \\
\left(\mathrm{cm}^{-3}\right)\end{array}$ & $\begin{array}{c}\text { Net } \mathrm{CO}_{2} \\
\text { (ppm) }\end{array}$ & 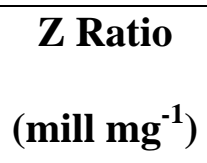 \\
\hline A & CNG & Accelerating & $7.58 \times 10^{5}$ & 68 & 6299 \\
\hline B & Diesel & Cruising & $1.10 \times 10^{5}$ & 66 & 942 \\
\hline $\mathrm{C}$ & Diesel & Accelerating & $2.46 \times 10^{5}$ & 122 & 1139 \\
\hline D & Diesel & Accelerating & $2.14 \times 10^{5}$ & 106 & 1141 \\
\hline $\mathbf{E}$ & CNG & Accelerating & $8.92 \times 10^{5}$ & 91 & 5538 \\
\hline $\mathbf{F}$ & CNG & Accelerating & $7.94 \times 10^{5}$ & 53 & 8466 \\
\hline G & CNG & Cruising & $1.24 \times 10^{5}$ & 95 & 738 \\
\hline
\end{tabular}

In our previous study (15), we monitored the emissions from 164 diesel and 98 CNG buses and determined median $\mathrm{Z}$ and standard error values of (1265 \pm 64$)$ and (7584 \pm 258) $\times 10^{6} \mathrm{mg}^{-1}$, respectively, and concluded that the median PN emission from the CNG buses was over six times higher than that from the diesel buses. Studying this data carefully, we were able to identify 87 diesel and 62 CNG buses that clearly accelerated from rest past the monitoring station. The respective $\mathrm{Z}$ and standard error values for these buses were found to be $(1285 \pm 98)$ and $(7629 \pm 332) \times 10^{6} \mathrm{mg}^{-1}$, respectively. We also identified 19 diesel and 11 CNG buses that cruised past the monitoring point without stopping. Two of these buses are shown as B and G in Fig 2 and Table 1 . The respective $\mathrm{Z}$ and standard error values for these diesel and CNG buses were found to be $(1030 \pm 254)$ and $(790 \pm 205) \times 10^{6} \mathrm{mg}^{-1}$ respectively. These values are summarised in Table 2, from which we conclude that the PN emission rates 
from an accelerating diesel bus is only about $25 \%$ greater than that from a similar bus that is cruising at a steady speed of $30-40 \mathrm{~km} \mathrm{~h}^{-1}$. However, the corresponding increase for the CNG buses was almost an order of magnitude. It is also observed that, when cruising, a diesel bus emits about 30\% more PN than a CNG bus while, when accelerating from rest, the CNG bus emits about six times more PN than a diesel bus.

Table 2: Median Z values for Diesel and CNG buses during cruising and acceleration from rest in Study 1. $Z_{\text {accel }}$ values are from Jayaratne et al (15).

\begin{tabular}{|l|l|l|l|}
\hline & $\mathrm{Z}_{\text {Cruise }}$ & $\mathrm{Z}_{\text {Accel }}$ & $\mathrm{Z}_{\text {Accel }} / \mathrm{Z}_{\text {Cruise }}$ \\
\hline Diesel & 1030 & 1285 & 1.25 \\
\hline CNG & 790 & 7629 & 9.66 \\
\hline $\mathrm{Z}_{\mathrm{CNG}} / \mathrm{Z}_{\text {Diesel }}$ & 0.77 & 5.94 & \\
\hline
\end{tabular}

3.2 Study 2 (dynamometer): The median PN emission rates of the 4 diesel and 5 CNG buses at each of the four steady-state engine loads is shown in Fig 3. The error bars indicate the respective $25 \%$ and $75 \%$ percentile values obtained from all the buses at each load. The PN emission rates increased with load for both types of buses. However, the difference in PN emission rate between the diesel and CNG buses decreased as the load increased. Statistically, the difference was significant at the three lowest loads but insignificant at the full power load. 


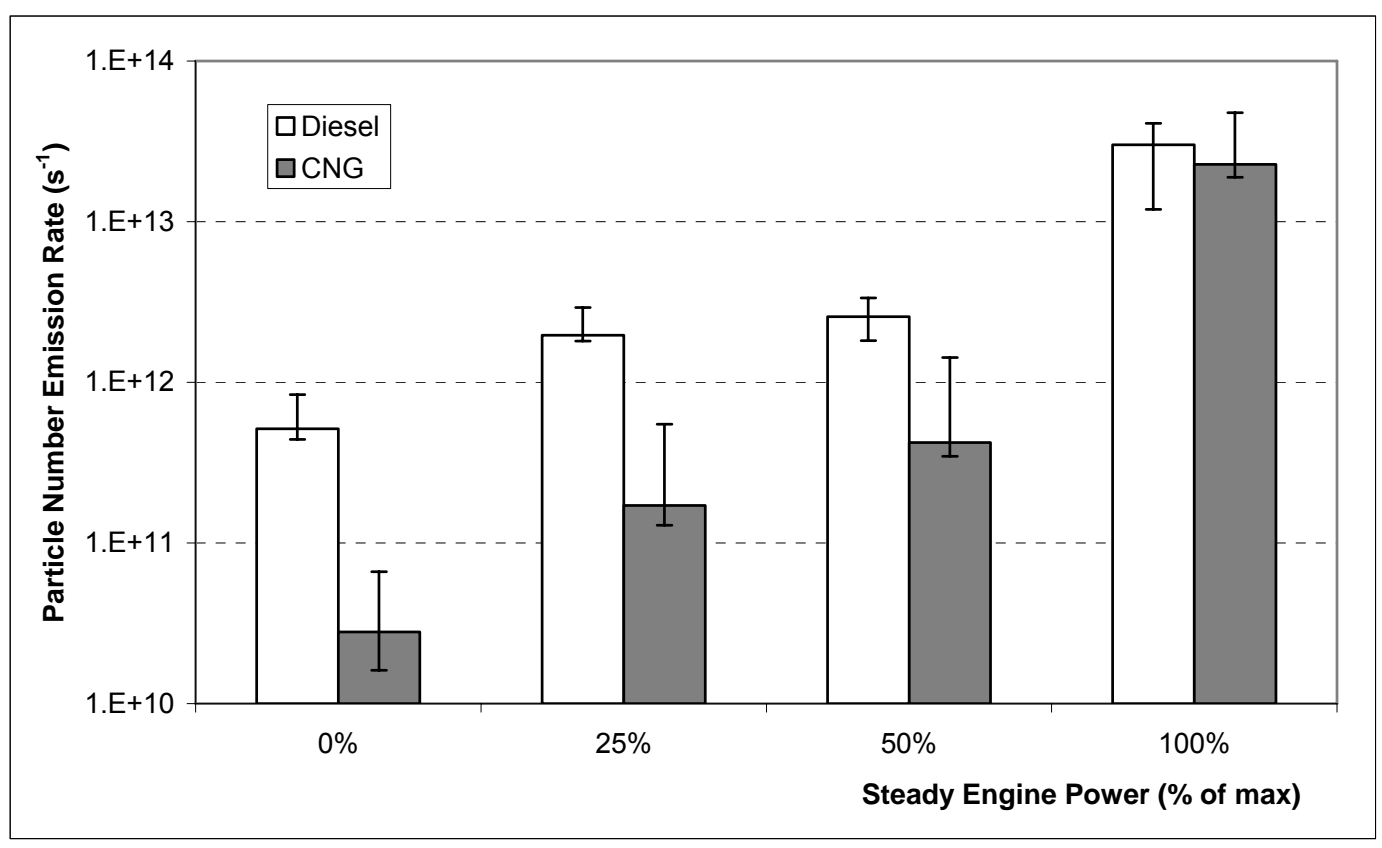

Fig 3: Median PN emission rates of the 4 diesel and 5 CNG buses at four steadystate engine loads in Study 2. The error bars indicate the $25 \%$ and $75 \%$ percentile values about the medians.

Fig 4 shows the engine conditions and emission concentrations during the testing of a diesel bus on a DT-80 transient cycle. This bus was a pre-Euro emission standard Volvo B10M (engine type THD101GC) with no after-treatment and had been in service for 16 years with mileage $1.04 \times 10^{6} \mathrm{~km}$. The large majority of the diesel fleet at the time consisted of similar buses with a minimum mileage of $5 \times 10^{5} \mathrm{~km}$. As stated earlier, the ages of the diesel buses in the fleet ranged from 6 to 23 years and at 16 years this example represented a typical diesel bus in the fleet.

Note how the load and the PN emission rate peak during each of the three accelerations from rest. We define the "initial acceleration" as the acceleration from rest in first gear. There are three such segments in each cycle. Following each period of initial acceleration, the driver raises the gears, reducing the load in three steps 
while continuing to accelerate. The power is the product of the speed and the load. For a given power setting, the load is a maximum when starting from rest and decreases as the speed increases. The load and the PN emissions peak during the initial acceleration where the bus is in first gear and then decrease at subsequent gear changes. At each gear change, the load drops but since the speed continues to increase, the power increases until the next gear change. The $\mathrm{CO}_{2}$ concentration is directly proportional to the fuel consumption rate and so increases with engine power. However, the PN emissions do not follow the power. These trends are also observed in the third segment of the cycle when the speed levels out at $80 \mathrm{~km} \mathrm{~h}^{-1}$ and the bus cruises at this constant speed. Each bus was tested over three DT-80 cycles, providing nine initial accelerations and three cruise segments. The mean peak PN emission rate of the nine initial accelerations and the mean PN emission rate over the three $80 \mathrm{~km} \mathrm{~h}^{-}$ ${ }^{1}$ cruise were $1.1 \times 10^{15} \mathrm{~min}^{-1}$ and $6.0 \times 10^{14} \mathrm{~min}^{-1}$ respectively.

Fig 5 shows the corresponding result for a CNG bus. This was a Scania L94UB, Euro II (engine type OSC9G) with a 2-way oxidation catalyst, 3-year old bus with a mileage of $1.86 \times 10^{5} \mathrm{~km}$. As for the diesel bus, this bus was typical of the CNG fleet at the time. The variation of the parameters are similar to the diesel bus except that the PN emission rate peaks much more sharply during the initial acceleration and show more pronounced changes during the subsequent gear changes. Over three DT-80 cycles, the mean peak PN emission rates at initial acceleration from rest and during the $80 \mathrm{~km} \mathrm{~h}^{-1}$ cruise for this bus were $2.5 \times 10^{16} \mathrm{~min}^{-1}$ and $1.2 \times 10^{15} \mathrm{~min}^{-1}$ respectively. 

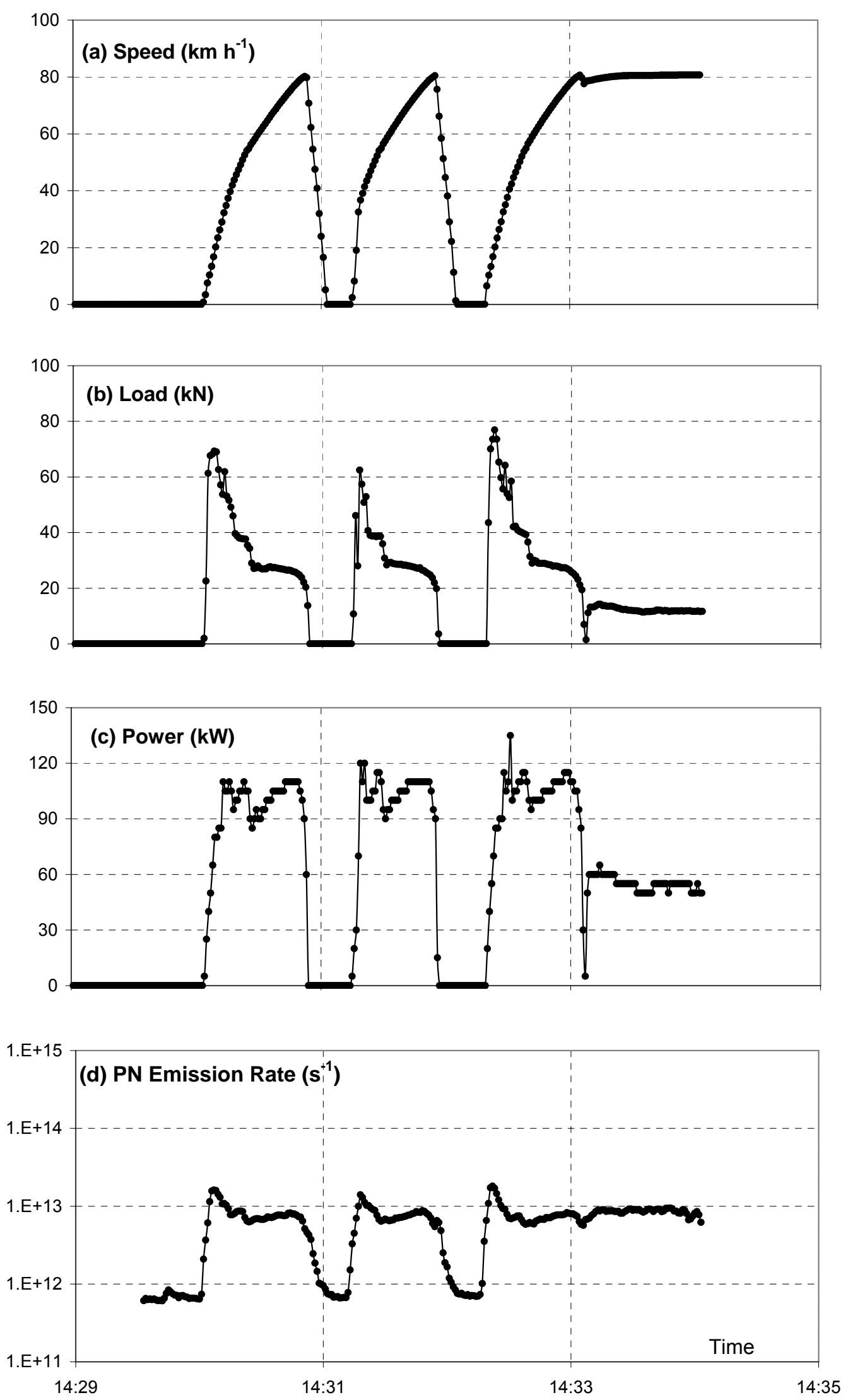
Fig 4: Parameters measured during a typical DT-80 transient cycle on a diesel bus. 

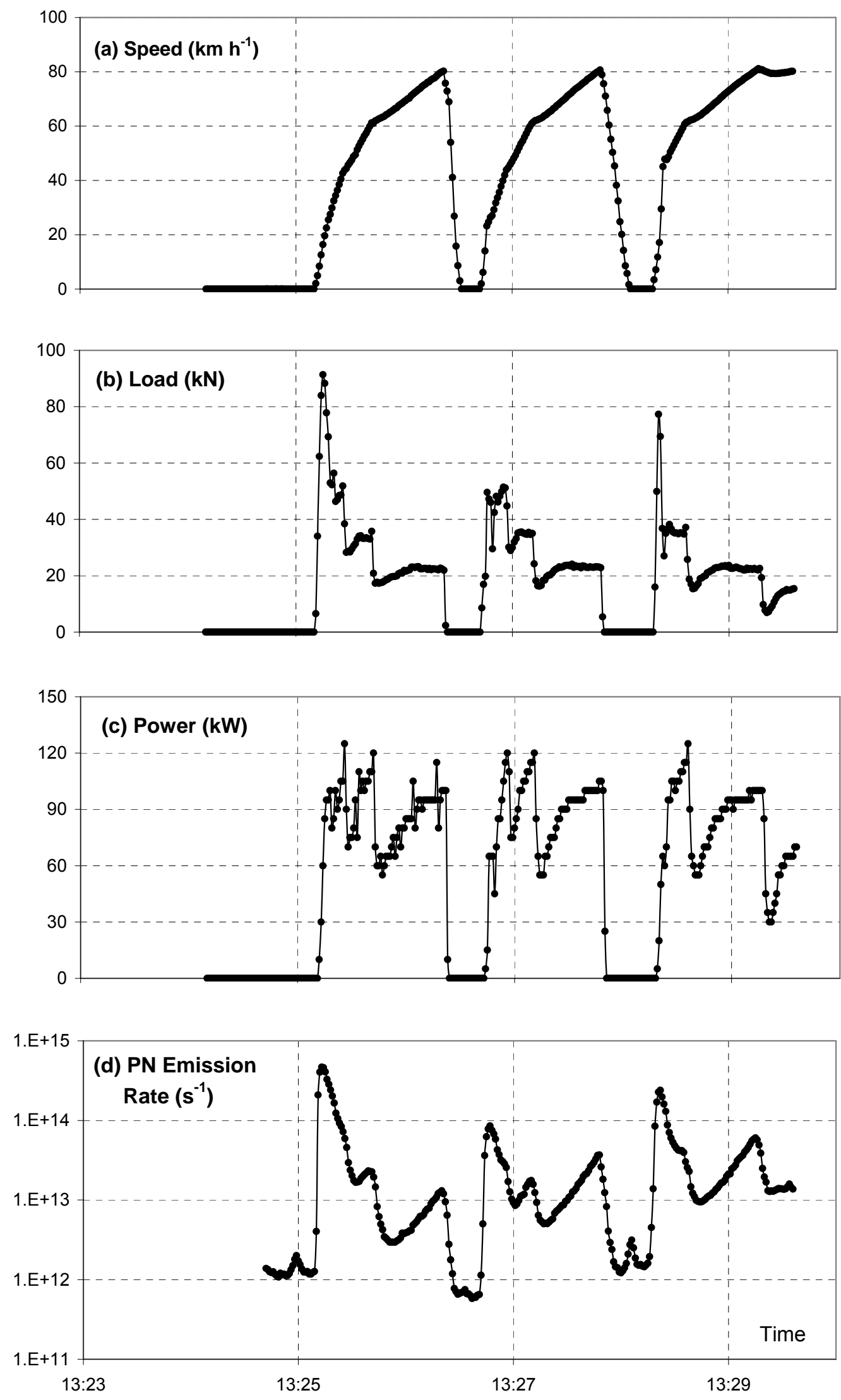
Fig 5: Parameters measured during a typical DT-80 transient cycle on a CNG bus. 
Table 3 gives the mean PN emission rates for the four diesel and five CNG buses tested at the three driving conditions. Here, mean values are used over median values because the number of sampling points is not identical in the three driving conditions.

Table 3: Mean PN emission rates derived for diesel and CNG buses under different driving conditions. 1: data from the DT-80 transient cycles; 2: data from the steady-state $100 \%$ power load study (Fig 3).

\begin{tabular}{|l|l|l|}
\hline & \multicolumn{2}{|l|}{ PN Emission Rate (particles s } \\
& -1 & \\
\hline Driving Condition & Diesel Buses & CNG Buses \\
\hline $80 \mathrm{~km} \mathrm{~h}^{-1}$ cruise $^{1}$ & $3.8 \times 10^{12}$ & $1.2 \times 10^{13}$ \\
\hline Full Power steady load $^{2}$ & $3.0 \times 10^{13}$ & $2.3 \times 10^{13}$ \\
\hline Initial Acceleration $^{1}$ & $1.8 \times 10^{13}$ & $2.0 \times 10^{14}$ \\
\hline
\end{tabular}

Fig 6 is a graphical representation of the mean PN emission rates derived in the full power steady-state mode (Fig 3), the $80 \mathrm{~km} \mathrm{~h}^{-1}$ cruise and initial acceleration modes from the DT-80 transient cycles for the diesel and CNG buses tested. From Fig 3, we see that, when at rest with the engine idling, the PN emission from a diesel bus was an order of magnitude higher than from a CNG bus. The difference decreased as the power increased and became comparable at steady full power operation. Although, the mean PN from the CNG buses was higher than from the diesel buses when they were both cruising at $80 \mathrm{~km} \mathrm{~h}^{-1}$, the difference was not statistically significant. There was no significant difference between the PN emission rates from the diesel buses when they were accelerating and when operating at steady full power. However, during initial acceleration, the CNG buses emitted almost an order of magnitude higher PN than during steady full power operation. Thus, in the initial acceleration 
stage, the PN emissions from the CNG buses were an order of magnitude higher than from the diesel buses. These results are broadly consistent with the kerbside measurements.

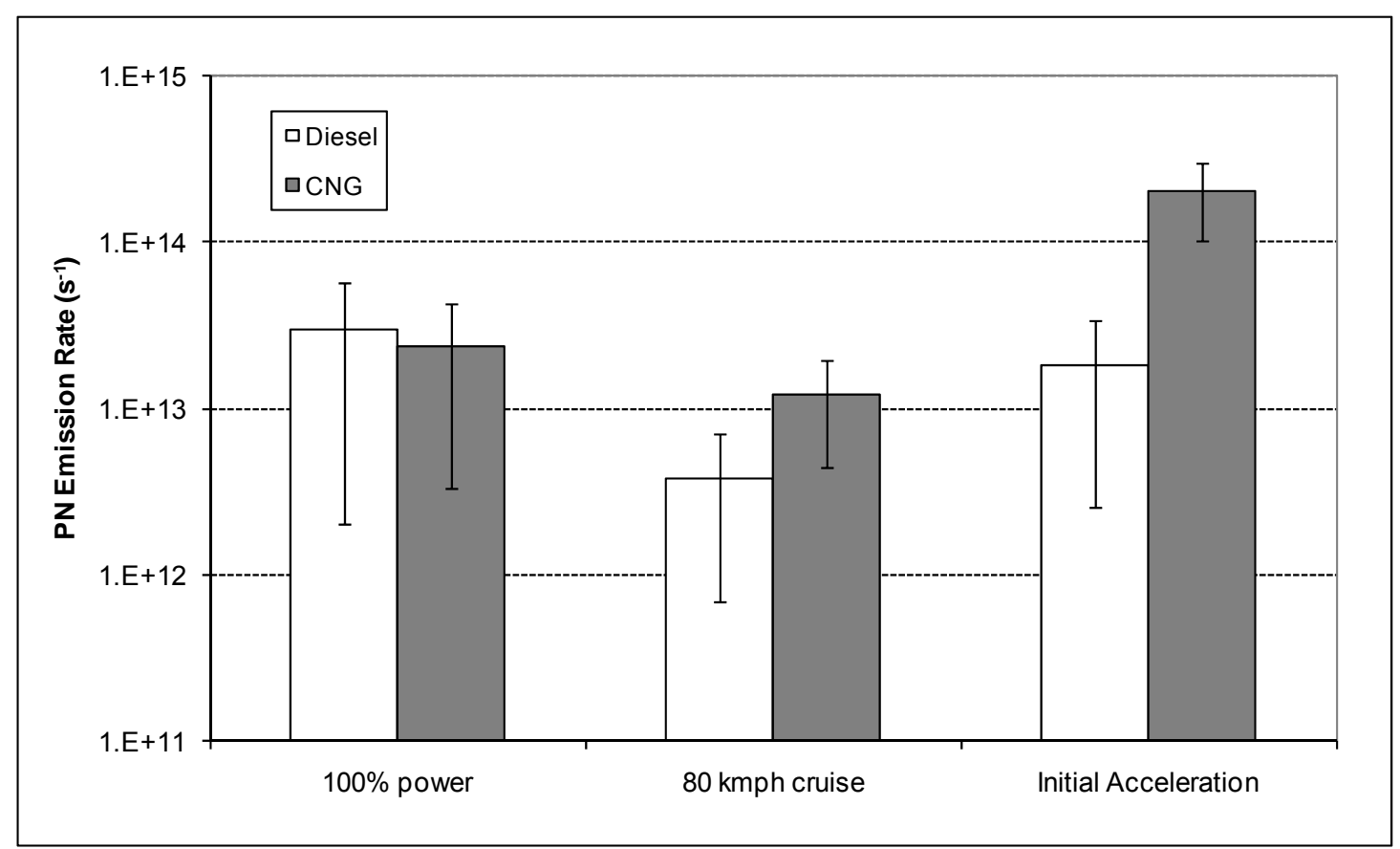

Fig 6: Graphical representation of the mean PN emission rates from the two types of buses under various driving conditions. The error bars represent standard deviations of the means.

Jayaratne et al. (12) showed that, under steady engine power at a uniform speed of 60 $\mathrm{km} \mathrm{h}^{-1}$, the median diameter of the emitted particles were $80-90 \mathrm{~nm}$ for the diesel buses and only $10-12 \mathrm{~nm}$ for the CNG buses. In the DT-80 tests, it was not possible to determine the particle sizes at high time resolution and, as such, we do not have a record of the particle sizes. However, there is good evidence in the literature that suggest that the increased particle numbers from CNG vehicles at high load occur in the nuclei mode $(3,7)$. In order to investigate the physical nature of the particles during the high load, high concentration periods, in Fig 7, we present the 
corresponding time sequence of the $\mathrm{PM}_{10}$ emission rate and tailpipe opacity measurements for the diesel bus presented in Fig 4.
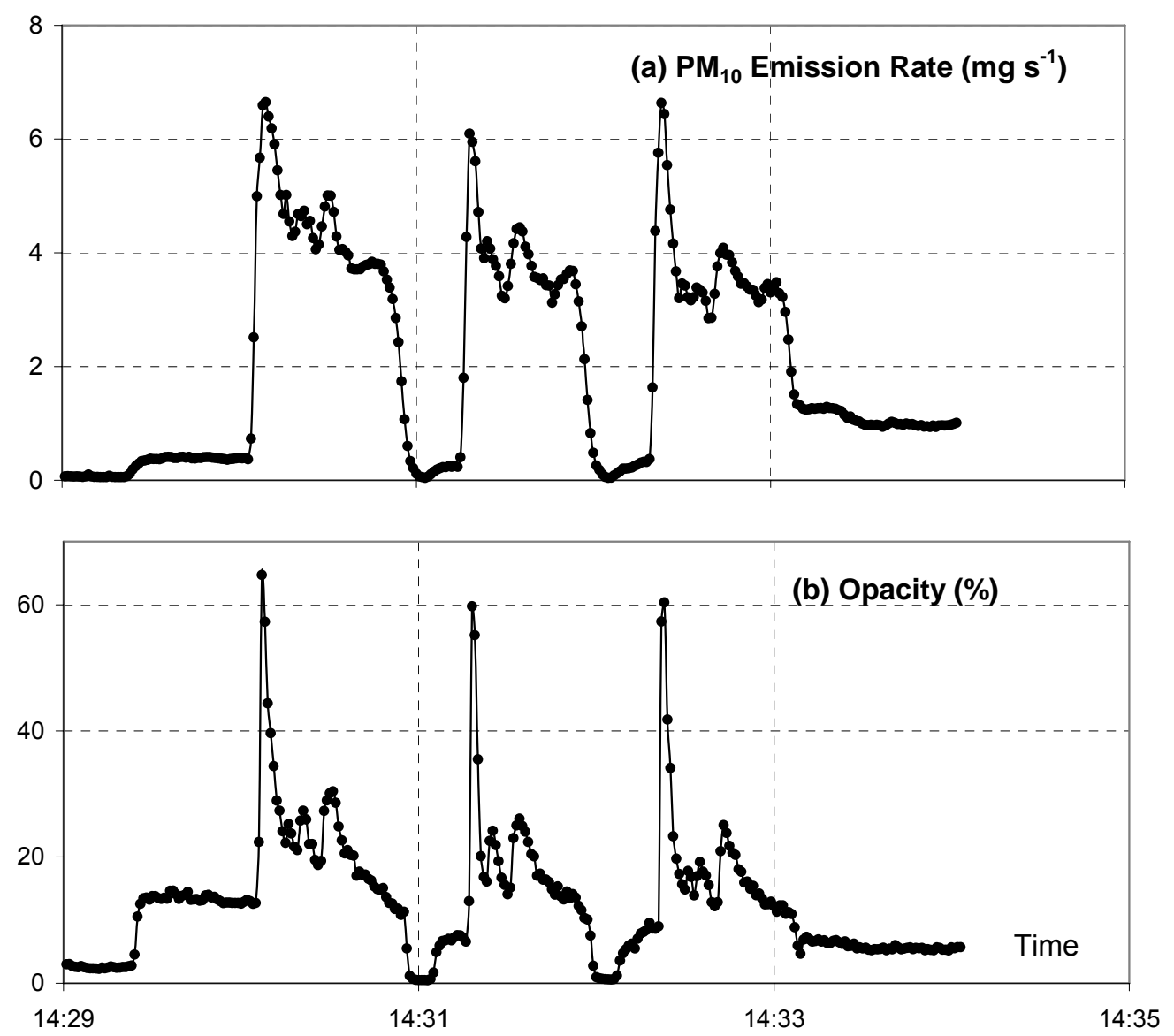

Fig 7: $\mathrm{PM}_{10}$ emission rate and tailpipe opacity measured during the DT-80 transient cycle on the diesel bus presented in Fig 4.

Note how both the $\mathrm{PM}_{10}$ emissions and the opacity peak sharply at first acceleration under high load. This is clearly indicative of a reduction in visibility due to the increased number of diesel exhaust particles. However, no such effect was observed with the CNG buses; the two parameters being virtually zero, even at high load. This result shows that, during high load, the large number of particles emitted by a CNG bus is below the size that may affect the opacity of the exhaust gas and, as suggested 
by Jayaratne et al. (12) may consist of semivolatile nanoparticles. The formation of volatile nanoparticles in diesel emissions is highly affected by the cooling and dilution processes and, therefore, the PN emissions can be highly variable (16). In addition, under high load conditions, spark ignition vehicles, such as CNG vehicles, are designed to operate at a richer fuel-air mixture to prevent engine knock, maximise engine torque and to protect the engine from excessive temperatures (17). Although this improves driving performance, it leads to high levels of emissions such as CO, volatile organic compounds and particulate matter. Maricq et al. (18) investigated particle number emissions from 21 petrol powered vehicles under transient conditions and concluded that the emissions correlated with vehicle acceleration, particularly during cold start. During heavy acceleration, the particle production per unit amount of fuel burned was also increased substantially; suggesting that the sharp increases in particle emission was not solely due to the greater exhaust air flow or higher fuel consumption. $\mathrm{CO}$ and total hydrocarbon emissions also followed a similar pattern to the particle emission. This is not surprising as all three emissions result from incomplete combustion that may occur due to a richer fuel-air mix.

At steady speeds, PN emission rates from diesel buses are generally greater than from CNG buses (Fig 3). However, during the initial acceleration segments of the DT-80 cycle, all CNG buses, irrespective of age, showed higher PN emissions than diesel buses. These two observations suggest that the higher PN emissions of CNG buses over diesel buses during acceleration is probably a consequence of the different ignition systems (spark ignition and compression ignition) rather than the difference in fuel type, although from our data alone, we cannot establish this hypothesis. 
In summary, during normal cruising or steady speed conditions under low engine loads, PN emissions from CNG buses are significantly lower than from diesel buses. However, at high loads, the PN emission rates from both diesel and CNG buses become comparable. When accelerating in first gear, the PN emission rate from CNG buses is an order of magnitude greater than from diesel buses of similar maximum power. However, these particles are too small to contribute to $\mathrm{PM}_{10}$ emissions or a reduction of visibility and may consist of semivolatile nanoparticles.

\section{Acknowledgements}

This work was supported by the Australian Research Council and Queensland Transport through Linkage Grant LP0775260. We would like to thank Jurgen Pasieczny and Ray Donato of Queensland Transport for arranging the logistics, the staff of the Busway Operations Centre, Brisbane, for their assistance during the busway measurements and Bill Duncan, Malcolm Knowles and Rod Chippendale for their invaluable advice and assistance during the dynamometer study. Olivier Weitten assisted with some of the data analysis. 


\section{References}

1. Goyal, S.P. Present scenario of air quality in Delhi: a case study of CNG implementation. Atmos. Environ. 2003, 37, 5423-5431.

2. Donaldson, K., Li, X.Y. and MacNee, W. Ultrafine (nanometre) particle mediated lung injury. J. Aerosol. Sci. 1998, 29, 553-560.

3. Greenwood, S.J., Coxon, J.E., Biddulph, T. And Bennett, J. An investigation to determine the exhaust particulate size distributions for diesel, petrol and compressed natural gas fuelled vehicles. SAE Technical Paper 961085. Society of Automotive Engineers. 1996.

4. Wang, W.G., Clark, N.N., Lyons, D.W., Yang, R.M., Gautam, M., Bata, R.M. and Loth, J.L. Emissions comparisons from alternative fuel buses with a chassis dynamometer testing facility. Environ. Sci. Technol. 1997, 31, 31323137.

5. Clark, N.N., Gautam, M., Rapp, B.L., Lyons, D.W., Graboski, M.S., McCormick, R.L., Alleman, T.L. and Norton, P. Diesel and CNG transit bus emissions characterization by two chassis dynamometer laboratories: Results and issues. SAE Technical Paper Series, 1999-01-1469. Society of Automotive Engineers. 1999.

6. Ayala, A., Kado, N.Y., Okamato, R.A., Holmen, B.A., Kuzmicky, P.A., Kobayashi, R. And Stiglitz, K.E. Diesel and CNG heavy-duty transit bus emissions over multiple driving schedules: Regulated pollutants and project overview. SAE Technical Paper Series, 2002-01-1722. Society of Automotive Engineers. 2002. 
7. Holmen, B.A. and Ayala, A. Ultrafine PM emissions from natural gas, oxidation-catalyst diesel and particle-trap diesel heavy-duty transit buses. Environ. Sci. Technol. 2002, 36, 5041-5050.

8. Lanni, T., Frank, B.P., Tang, S., Rosenblatt, D. and Lowell, D. Performance and emissions evaluation of compressed natural gas and clean diesel buses at New York City’s metropolitan transit authority. SAE Technical Paper Series, 2003-01-0300. Society of Automotive Engineers. 2003.

9. Ullman, T.L., Smith, L.R., Anthony, J.W., Slodowske, W.J., Trestrail, B., Cook, A.L., Bunn, W.B., Lapin, C.A., Wright, K.J. and Clark, C.R. Comparison of exhaust emissions, including toxic air contaminants, from school buses in compressed natural gas, low emitting diesel, and conventional diesel engine configurations. SAE Technical Paper Series, 2003-01-1381. Society of Automotive Engineers. 2003.

10. Nylund, N., Erkkila, K., Lappi, M. and Ikonen, M. Transit Bus Emission Study: Comparison of emissions from diesel and natural gas buses. Research Report PRO3/P5150/04. Technical Research Centre, VTT Processes, Finland. 2004.

11. Kado, N.Y., Okamato, R.A., Kuzmicky, P.A., Kobayashi, R., Ayala, A., Gebel, M.E., Rieger, P.L., Maddox, C. and Zafonte, L. Emissions of toxic pollutants from compressed natural gas and low sulphur diesel-fuelled heavyduty transit buses tested over multiple driving cycles. Environ. Sci. Technol. 2005, 39, 7638-7649.

12. Jayaratne, E.R., Ristovski, Z.D., Meyer, N. and Morawska, L. Particle and Gaseous Emissions from Compressed Natural Gas and Ultralow Sulphur 
Diesel-Fuelled Buses at Four Steady Engine Loads. Sci Total Environ. 2009, 407, 2845-2852.

13. Holmen. B.A. and Qu, Y. Uncertainty in particle number modal analysis during transient operation of compressed natural gas, diesel, and trap-equipped diesel transit buses. Environ. Sci. Technol. 2004, 38, 2413-2423.

14. Jayaratne, E.R., Morawska, L., Ristovski, Z.D. and He, C. Rapid identification of high particle number emitting on-road vehicles and its application to a large fleet of diesel buses. Environ. Sci. Technol. 2007, 41, 5022-5027.

15. Jayaratne, E.R., He, C., Ristovski, Z.D., Morawska, L. and Johnson, G.R. A comparative investigation of ultrafine particle number and mass emissions from a fleet of on-road diesel and CNG buses. Environ. Sci. Technol. 2008, 42, 6736-6742.

16. Khalek, I.A., Kittelson, D. and Brear, F. The influence of dilution conditions on diesel exhaust particle size distribution measurements. SAE Technical Paper Series, 1999-01-1142. Society of Automotive Engineers. 1999.

17. Kean, A.J., Harley, R.A. and Kendall, G.R. Effects of vehicle speed and engine load on motor vehicle emissions. Environ. Sci. Technol. 2003, 37, 3739-3746.

18. Maricq, M.M., Podsiaklik, D.H. and Chase, R.E. Examination of the sizeresolved and transient nature of motor vehicle particle emissions. Environ. Sci. Technol. 1999, 33, 1618-1626. 